\title{
Experimental Study of the Level of Manual Performance Disability Caused by Exposure to Hand-Arm Vibration Among Automobile Casting Workers
}

\author{
Azar Soltani ${ }^{1}$, Mohsen Aliabadi ${ }^{* 2}$, Rostam Golmohammadi ${ }^{3}$, Magid Motamedzade ${ }^{3}$
}

1. MSc Student, Department of Occupational Hygiene, School of Public Health, Hamadan University of Medical Sciences, Hamadan, Iran

2. Center of Excellence for Occupational Health, Occupational Health and Safety Research Center, School of Public Health, Hamadan University of Medical Sciences, Hamadan, Iran

3. Center of Excellence for Occupational Health, Research Center for Health Sciences, School of Public Health, Hamadan University of Medical Sciences, Hamadan, Iran

\begin{tabular}{ll}
\hline \multicolumn{2}{c}{ Article Info } \\
\hline Original Article \\
Received: & 12 June 2018 \\
Accepted: & 13 July 2018 \\
Published Online & 13 July 2018
\end{tabular}

DOI: $10.30699 /$ jergon.6.1.40

Use your device to scan and read the article online

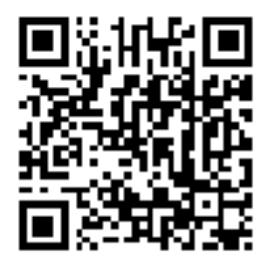

Corresponding Information

\section{Mohsen Aliabadi}

Center of Excellence for Occupational Health, Occupational Health and Safety Research Center, School of Public Health, Hamadan University of Medical Sciences, Hamadan, Iran

E-mail:

mohsen.aliabadi@umsha.ac.ir

\section{Abstract}

Background: Exposure to hand-arm vibration is one of the most common physical harmful factors. The purpose of this study was Experimental study of the level of manual performance disability caused by exposure to hand-arm vibration among automobile casting workers.

Methods: This study was performed on 53 casting workers as case group and 28 controls as control group. The measurement of the vibration of the worker's arms and hands was carried out in accordance with the ISO 5349 standard. The level of manual performance disability was evaluated using skeletal-muscular, sensory-neural and vascular tests. Also, a questionnaire was used for the level of disability of the arm, shoulder and hand DASH. Data were analyzed using SPSS16.

Results: The 8-hour vibration exposure was $8.33 \mathrm{~m} / \mathrm{s}^{2}$ (4.49), which exceeded the permissible level. Skill and dexterity, fingers and grip strength of the dominant hand in the case group were decreased by $4 \%, 13.3 \%$ and $11 \%$, respectively $(P<0.05)$. The regeneration time of the dominant hand in the case group was $41.2 \%$ higher than the control group $(P<0.05)$. Sensory-neurological complications increased in the case group compared to the control group, however, it was not statistically significant. The DASH score in the case group was 10.7 (13.4) and the control group was 4.1 (5.1).

Conclusion: Hand-arm manual performance disability in workers exposed to vibration decreased from $4 \%$ to $14 \%$, which confirmed the DASH score. In addition, workers showed a higher level of vascular complications compared with sensory-neurological complications.

Keywords: Hand-arm vibration, Manual performance disability, Casting worker

Copyright (C) 2018, Journal of Ergonomics. This is an open-access article distributed under the terms of the Creative Commons Attribution-noncommercial 4.0 International License which permits copy and redistribute the material just in noncommercial usages, provided the original work is properly cited

How to Cite This Article:

Soltani A, Aliabadi M, Golmohammadi R, Motamedzade M. Experimental Study of the Level of Manual Performance Disability Caused by Exposure to Hand-Arm Vibration Among Automobile Casting Workers. J Ergon. 2018; $6(1): 40-49$ 


\section{مقاله يزوهشى}

\section{بررسى تجربى سطح ناتوانى عملكرد دستى ناشى از مواجهه با ارتعاش دست ـ بازو در كارگران شاغل در يك صنعت ريخته}

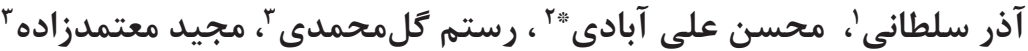

I. دانشجوى كارشناسى ارشد مهندسى بهداشت حرفهاى، دانشكدة بهداشت، دانشكاه علوم يزشكى همدان، همدان، ايران

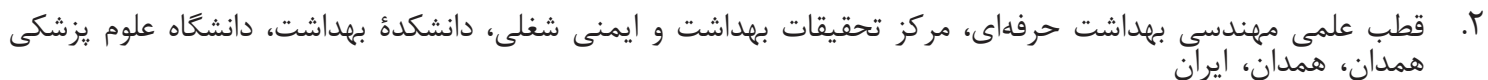

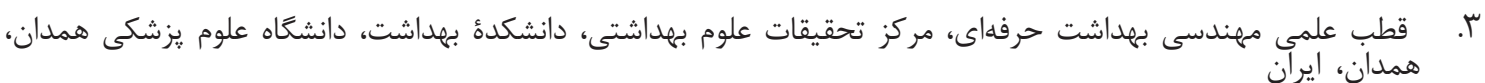

\begin{tabular}{|c|c|c|}
\hline جكيده & & 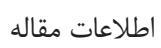 \\
\hline زمينه و هدف: مواجهه با ارتعاش دست ـ بازو از جمله عوامل زيان آور فيزيكى رايج است. هدف از اين مطالعه & $\mid r q V / \cdot r / r r$ & \\
\hline بررسى تجربى سطح ناتوانى عملكرد دستى ناشى از مواجهه با ارتعاش دست ـ بازو در كاركران شاغل در يك & $\mid r q V / \cdot F / r T$ & \\
\hline صنعت ريختهَرى است. & $\mid r q V / \cdot F / T 4$ & 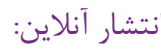 \\
\hline
\end{tabular}

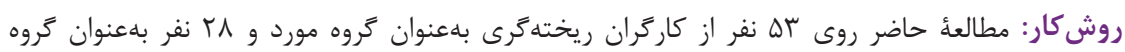

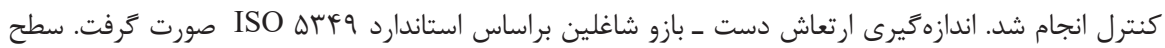

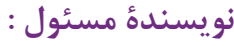

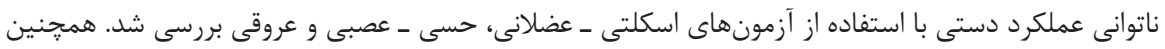

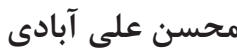

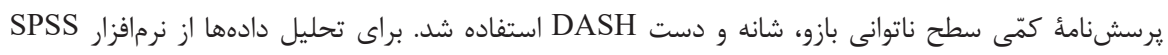

نسخأ 19 استفاده شد.

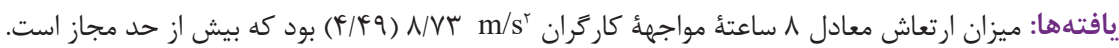

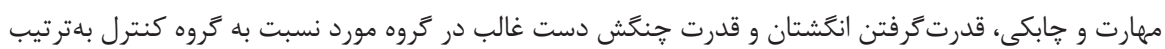

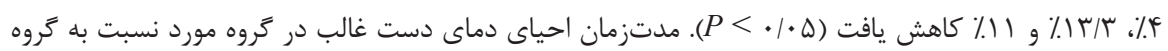

قطب علمى مهنى على آبادى مرسى بهداشت

حرفهاى، مركز تحقيقات بهدئ بهداشت

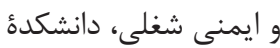

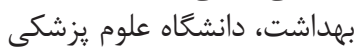

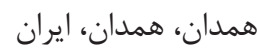

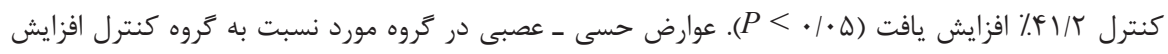

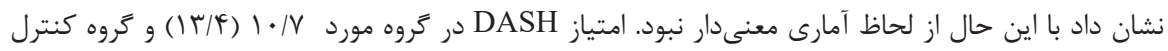

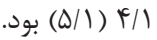

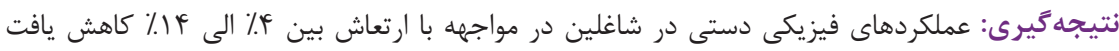

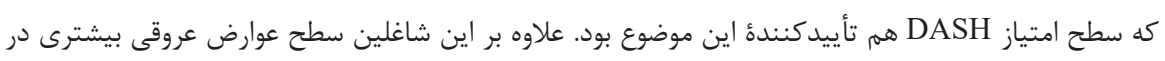
مقايسه با عوارض حسى ـ عصبى نشان دادند.

بست الكترونيك:

Mohsen.aliabadi@umsha.ac.ir

وازههاى كليدى: مواجهو شغلى ارتعاش دست و بازو، ناتوانى عملكرد دستى، كارگر ريختهرىى

تماس مستقيم با اعضا و اندامها مى تواند در محدوديتهاى

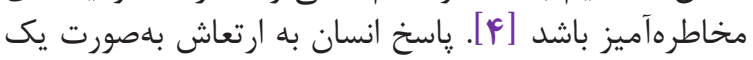

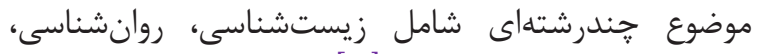
بيومكانيك و مهرندسى است [هاء

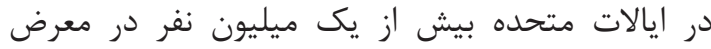

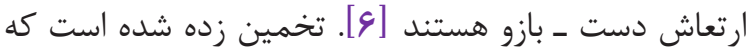

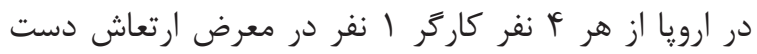

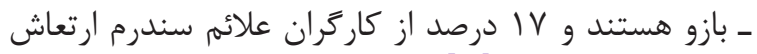

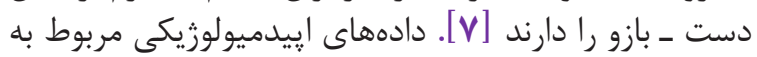

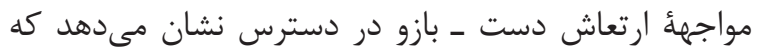

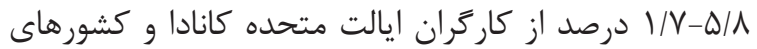

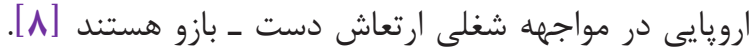

مقدمه

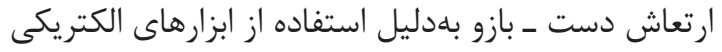

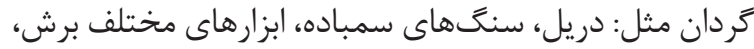

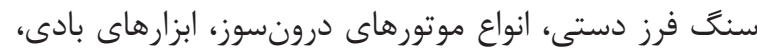

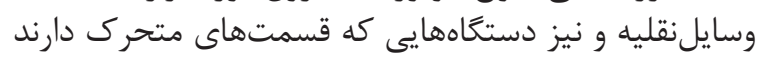

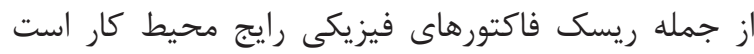

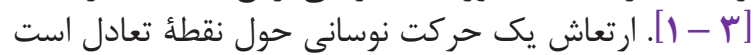
و يكى از عوامل همراه با صدا در محيطهاى صنى صنعتى است.

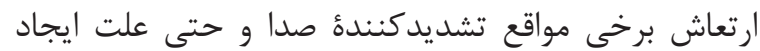

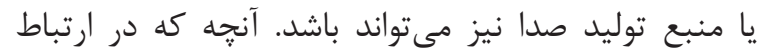

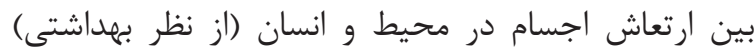

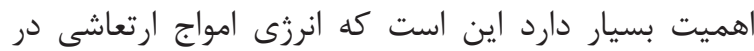




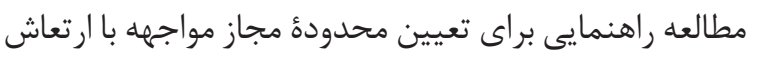

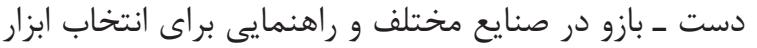

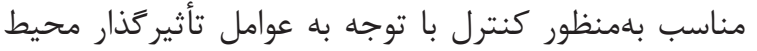
كار و تدوين دستور العمل بها باشد. توجه به

\section{مواد و روشها}

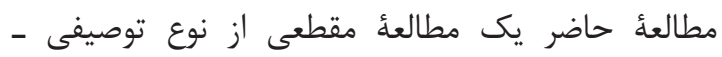

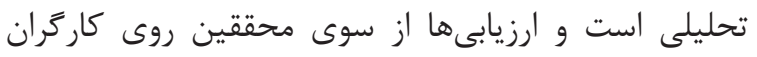

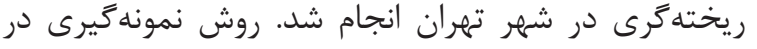

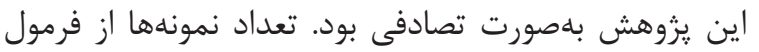

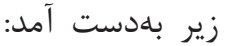

$$
n=\frac{\left(\sigma_{1}^{2}+\sigma_{2}^{2}\right)\left(z_{1} \frac{\alpha}{2}+z_{1-\beta}\right)^{2}}{\left(\mu_{1}-\mu_{2}\right)^{2}}
$$

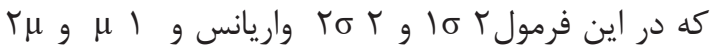

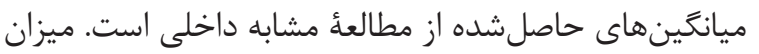

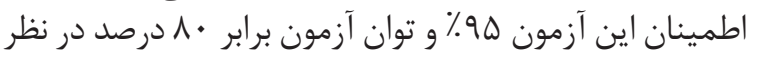

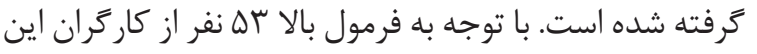

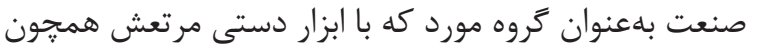

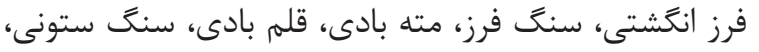

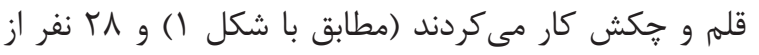

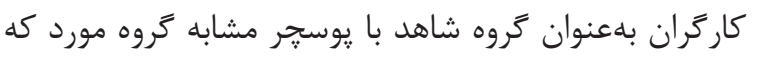

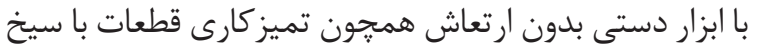
و رنغَ كارى كار مى كردند، مطالعه شدند.

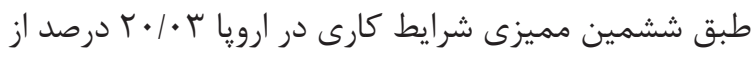

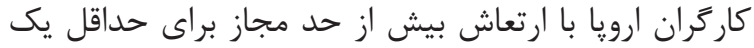

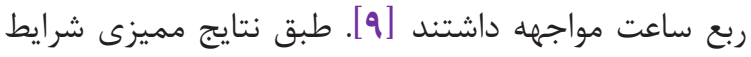

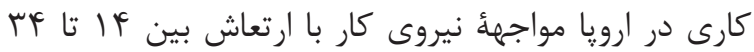

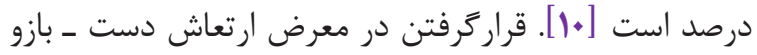

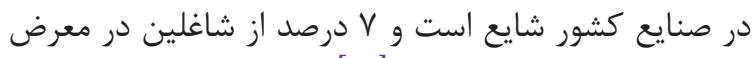
ارتعاش دست ـ بازو هستند [11].

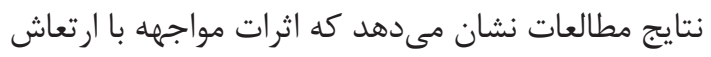

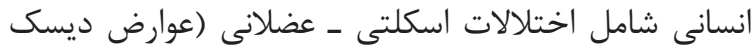

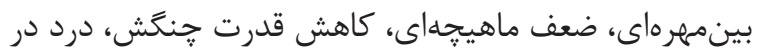

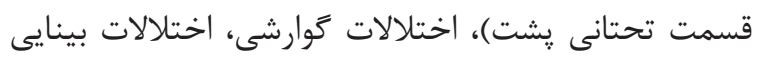

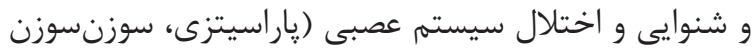

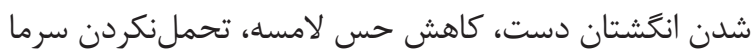

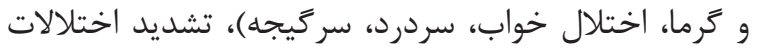

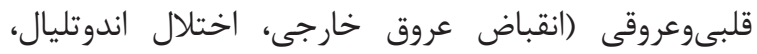

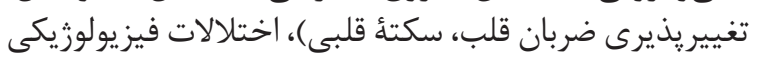

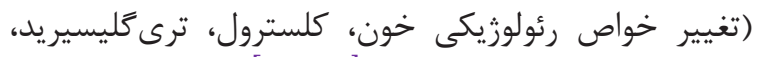

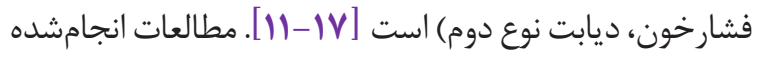

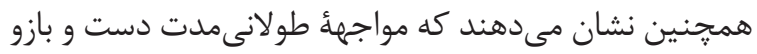

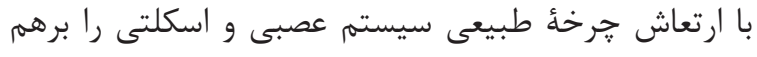

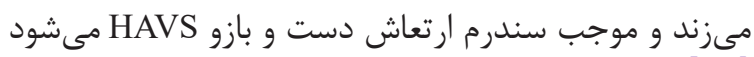

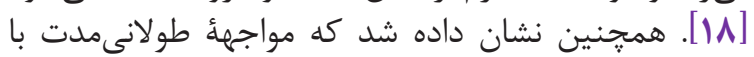

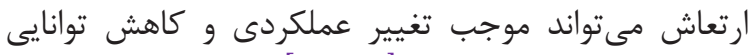

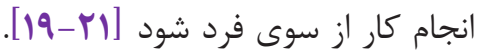

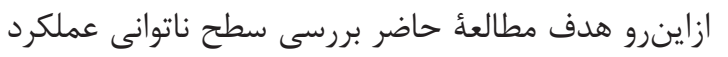

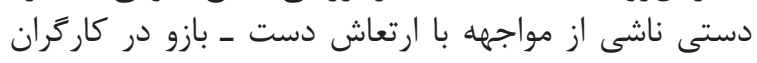

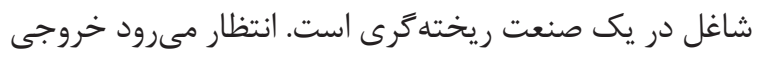
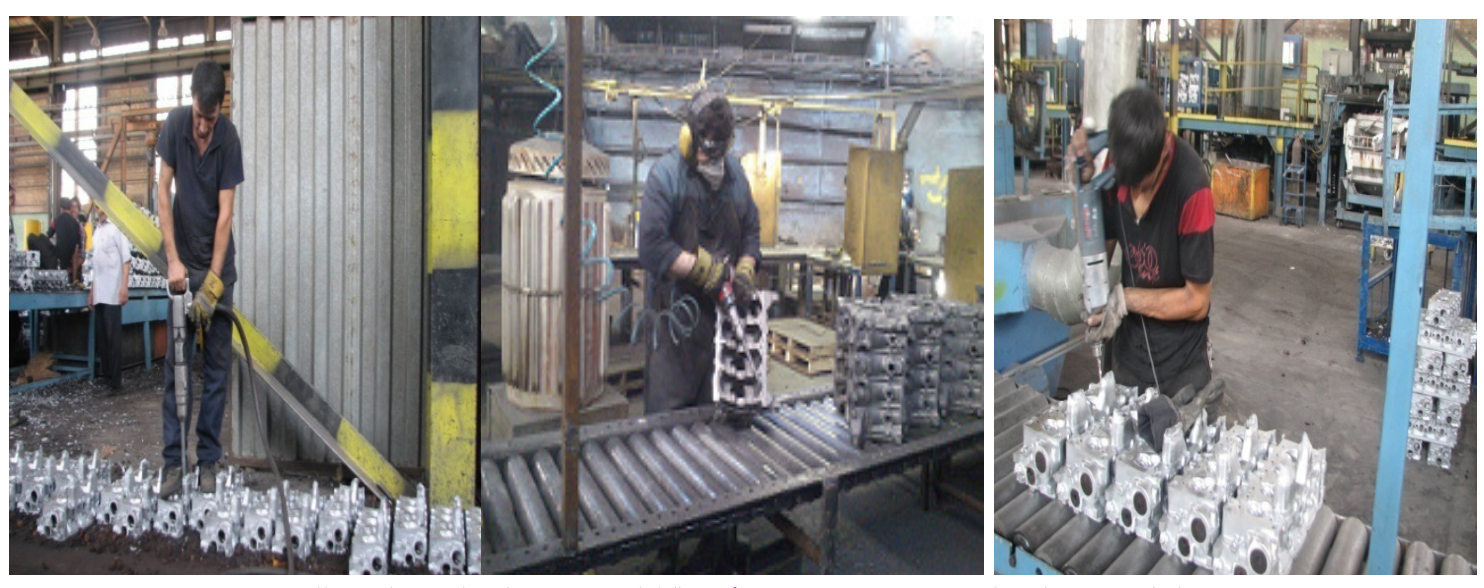

شكل ا. ابزار مر تعش استفادهشه در شركت ريختهكرى قطعات خودروى انتخابى در اين مطالعه

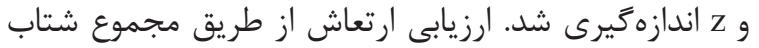

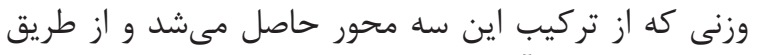

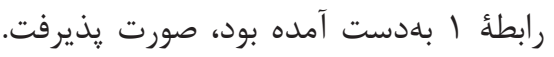

در اين مطالعه ارتعاش دست ـ بازو با توجه به ساعات

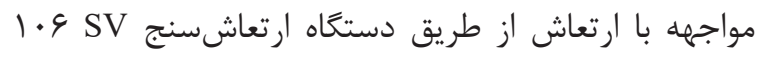
X, y مطابق با استاندارد Svantek

$$
\mathrm{A}(8)=a_{h w} \sqrt{\frac{T}{T_{0}}} \quad: \text { r }
$$




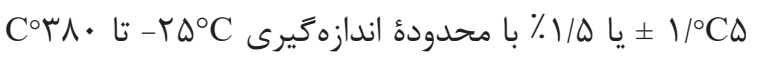

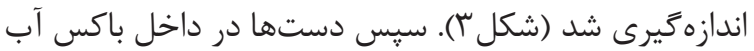

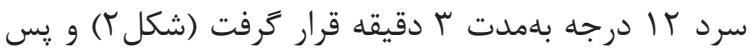

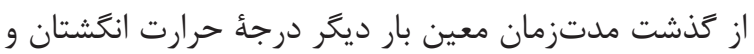

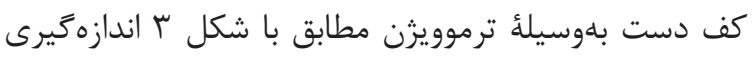

آزمون حسى ـ عصبى بلهوسيلة كيت مونوفيلامان با قابليت

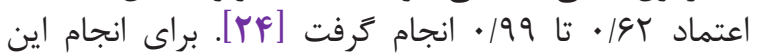

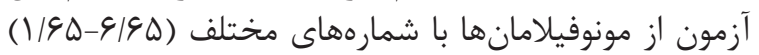

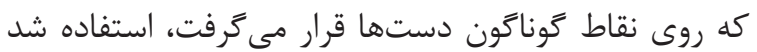

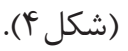

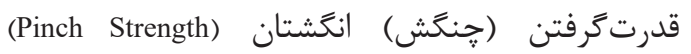

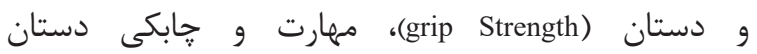
از جمله آزمونهاى اسكلتى عضلانى (Skill and dexterity) انجامشده در اين مطالعه بود.

قدرت جنَش انشَشتان از طريق Pinch gauge با ميزان

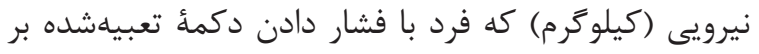

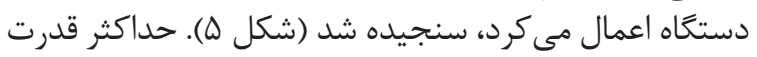
جنگَش دستان با نيروسنج هيدروليكى ( (Jamar

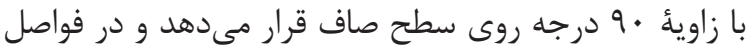

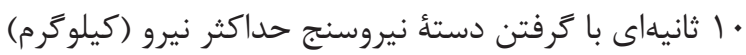

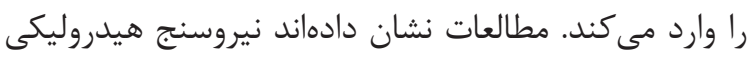

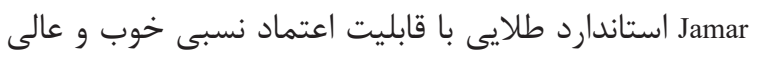

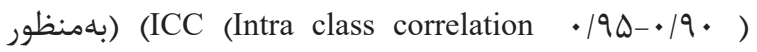

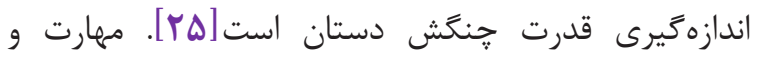

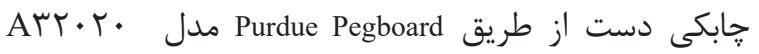

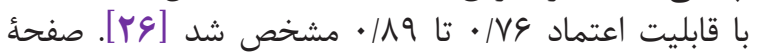
قعدادى سوراخ دارد كه فرد مىبايست

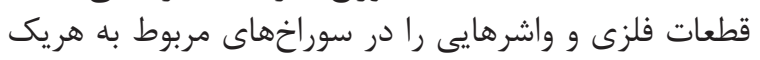

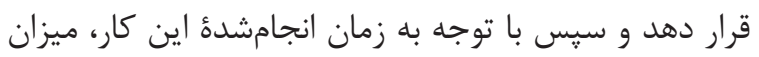

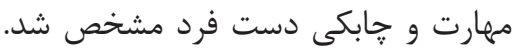

a رابطة ا برآيند شتاب ارتعاش است كه در آن a

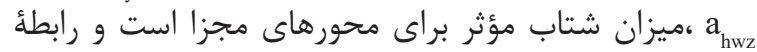

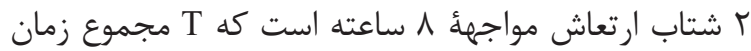

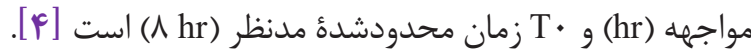
دادههاى كيفى عوارض مواجهه با ارتعاش دست ـ بازو

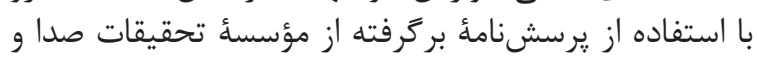

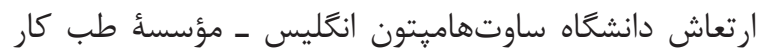

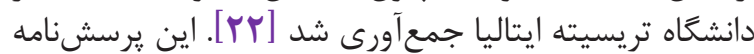

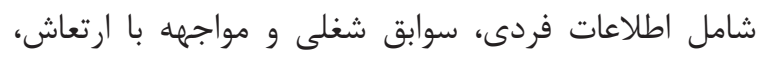

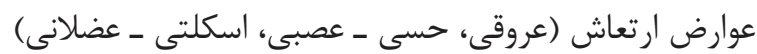
و سوابق يزشكى كارگر بود.

در اين مطالعه از يرسشنامه ديخرى تحتعنوان DASH (The Disabilities of the Arm, Shoulder and Hand) شد كه سطح ناتوانى افراد در مواجهه با ارتعاش دست - بازو

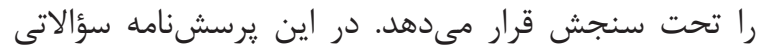

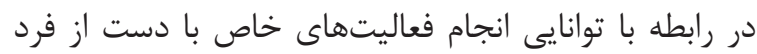

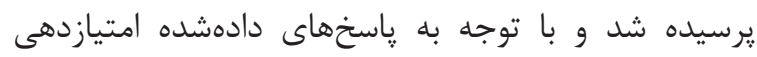

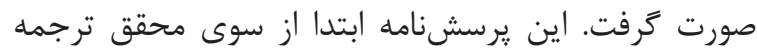

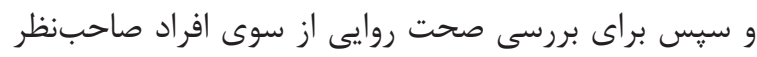

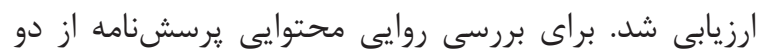

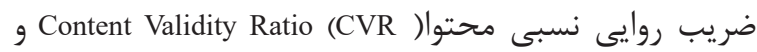

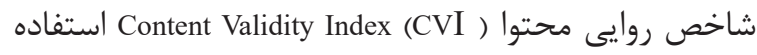

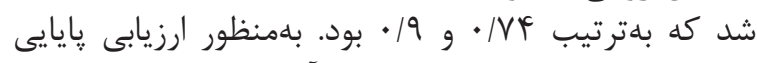

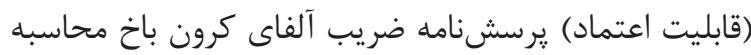

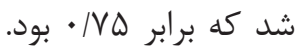

سطح عينى ناتوانى افراد در مواجهه با ارتعاش (اسكلتى

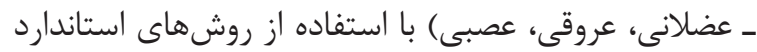

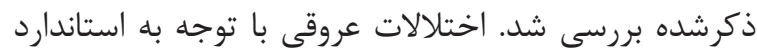

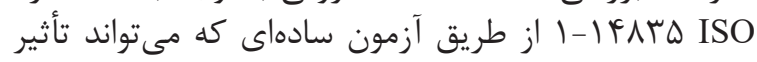

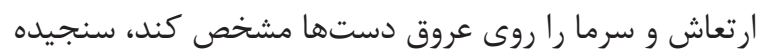

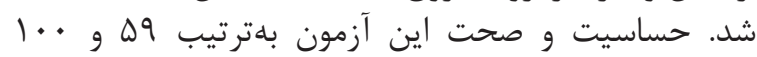

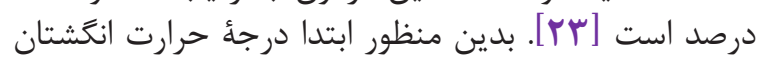

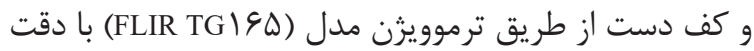

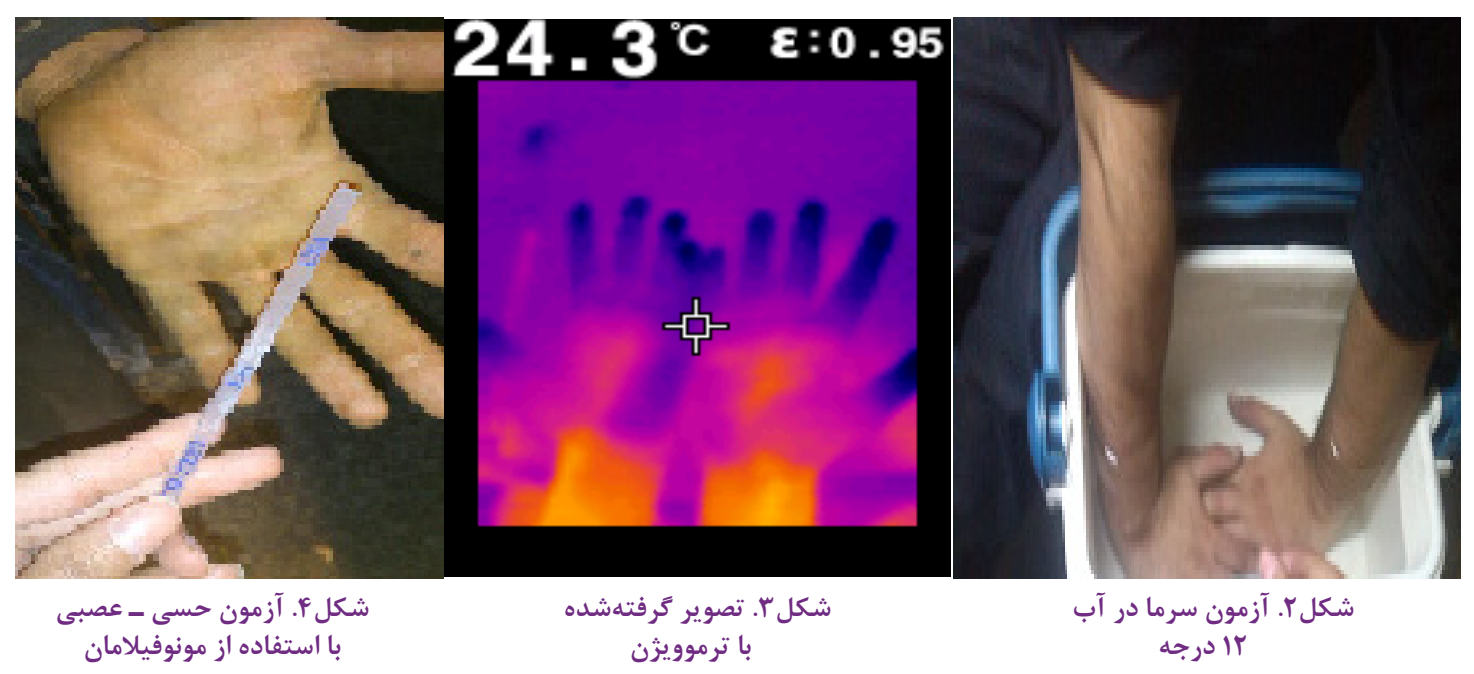




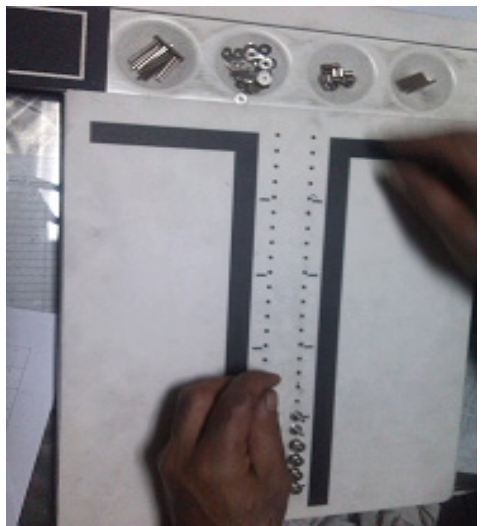

شكل V. آزمون مههارت و حابكى انَشتتان

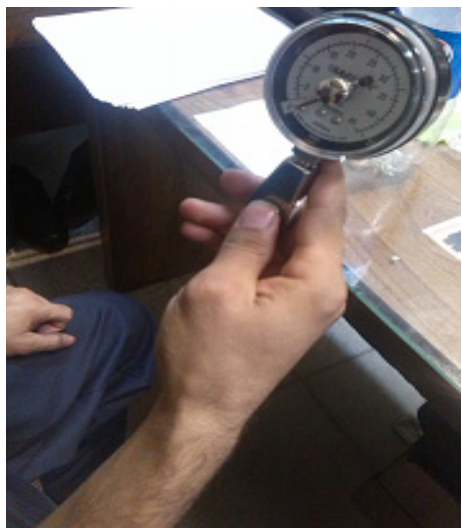

شكل 9. آزمون قدرت جنَگش انََشتان

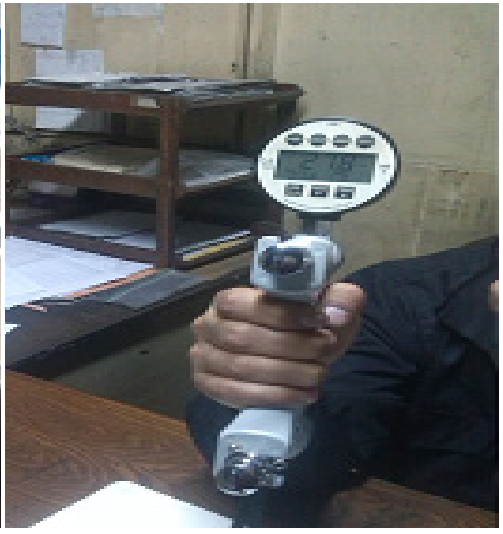

شكله. آزمون قدرت جنَشَ دستان
مربوط به علائم مرتبط با بروز نشانكان ارتعاش دست و بازو

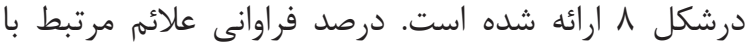

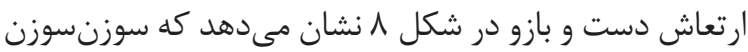

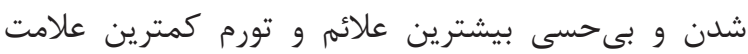

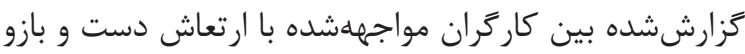

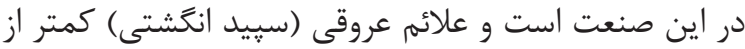
اختلالات اسكلتى ـ عضلانى است. براساس نتايج به دست ضصآمده، در شاغلين در

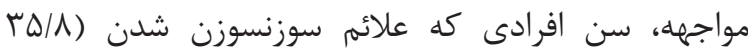

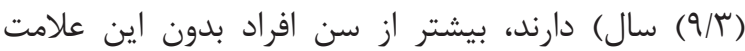

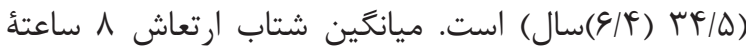

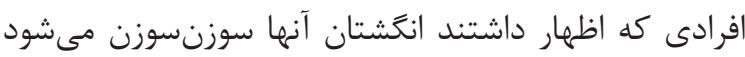

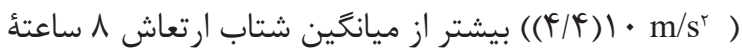

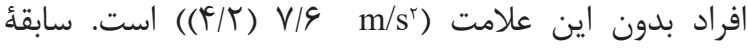

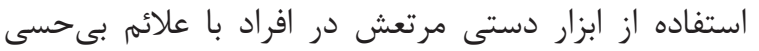

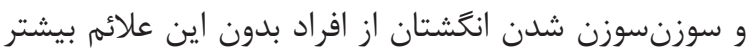

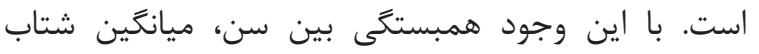

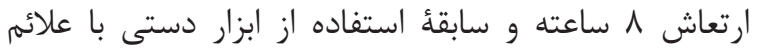

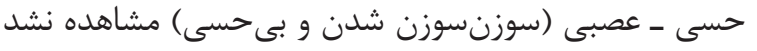
.$(P>\cdot / \cdot \Delta)$

با توجه به نتايج نشاندادهده در شكل 1 همأ علائم إنمان

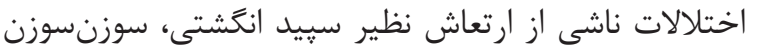

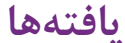

در اين مطالعه ميانخين سنى (انحراف معيار) كروه مورد ايز

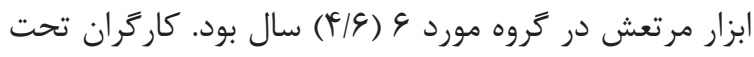

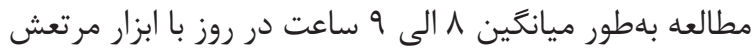

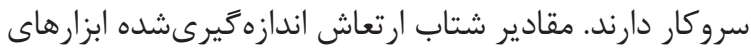

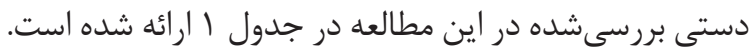

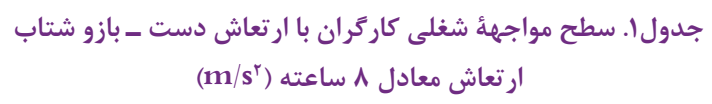

\begin{tabular}{|c|c|c|c|}
\hline حداكثر & حداقل & انحرافمعيار & ميانغين \\
\hline $19 / \mathrm{VA}$ & r/NQ & $F / 4 q$ & $N / V r$ \\
\hline
\end{tabular}

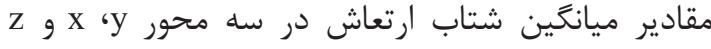

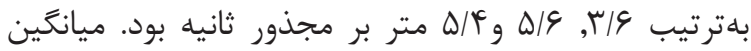

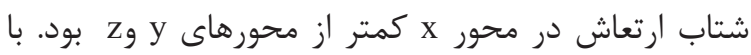

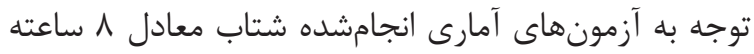

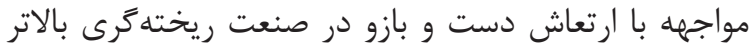
از حد مجاز مواجهو كشورى (r متر بر مجذور ثانيت دانيه) قرار بالاتر داشت [F] نتايج حاصل از دادهاى جمعآورىشده از يرسشنامة

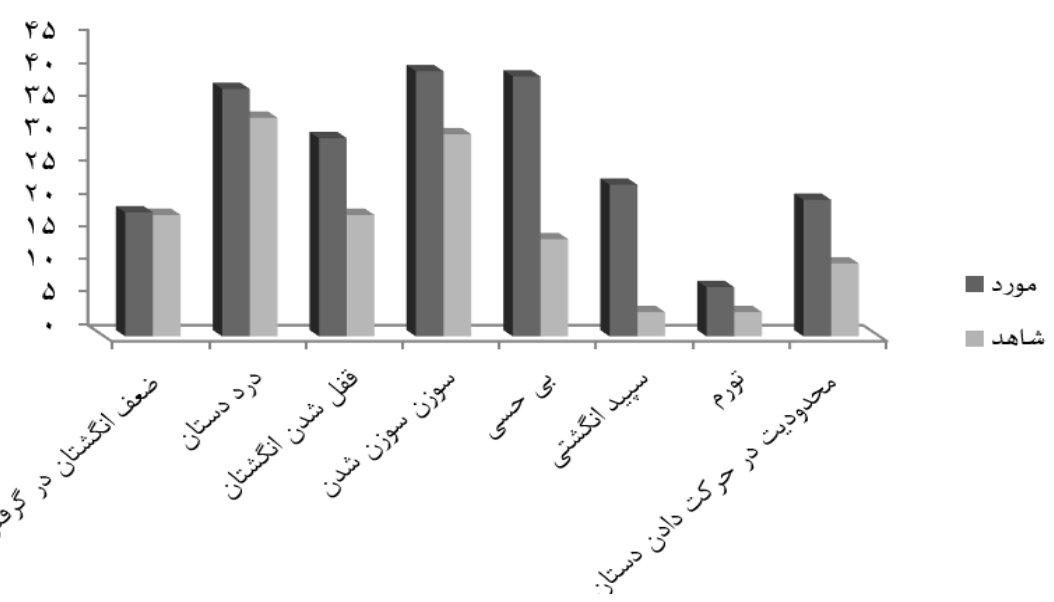

شكل ^. علائم مر تبط با بروز نشانغان ارتعاش دست و باز 
همبستگى وجود دارد (ه • |.>P و ضريب همبستخى ييرسون

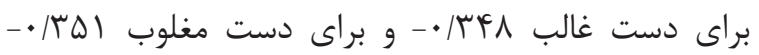

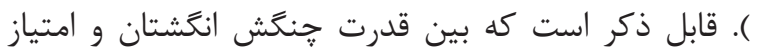
DASH با توجه به جدول ب، ميانگين قدرتگرفتن دست و نيز

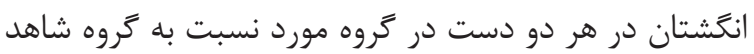

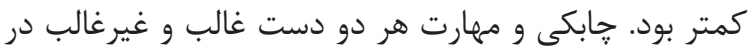

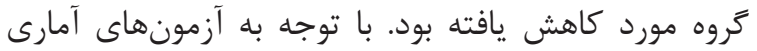

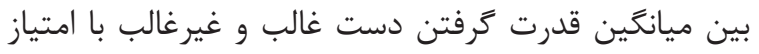

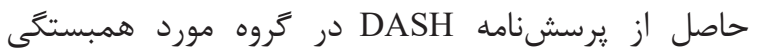

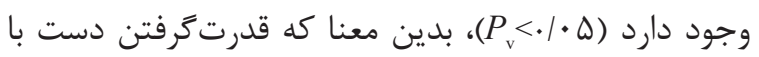

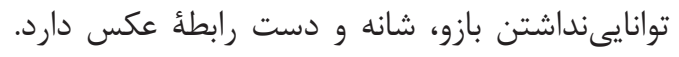

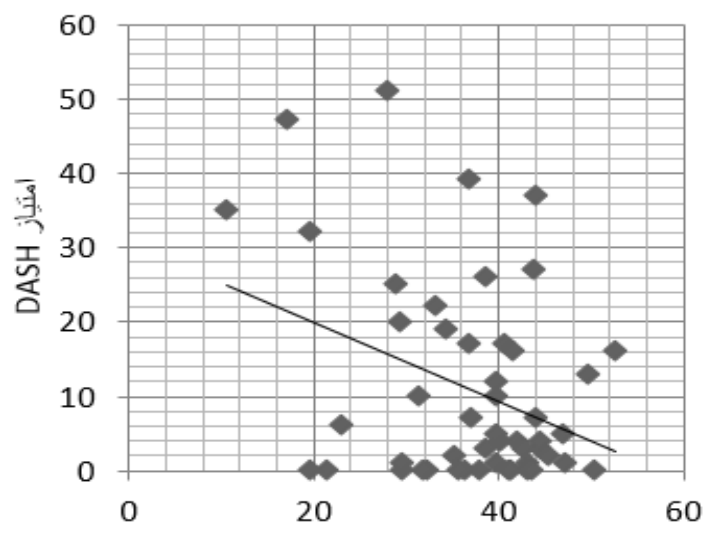

شكل •1. همبستكى بين قدرت جنَّش دست غيرغالب (كيلوكرم) و امتياز DASH
شدن، بى حسى، قفل شدن انگشتان، تورم، درد، ضعف انخشتان

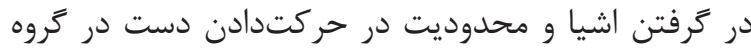

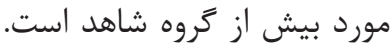

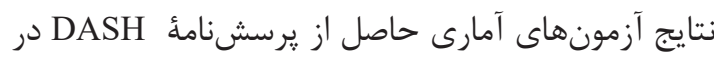

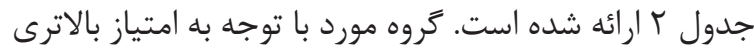

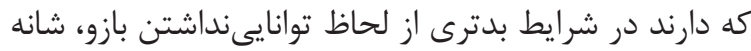

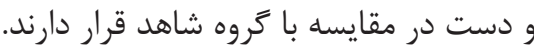

در اين مطالعه همبستخى امتياز DASH و قدرت غرفتن

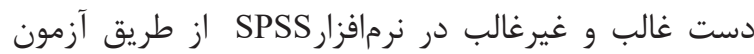

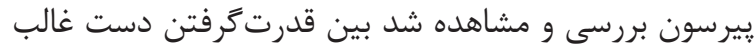
(شكل 9) و نيز دست مغلوب (شكل • (1) با امتياز

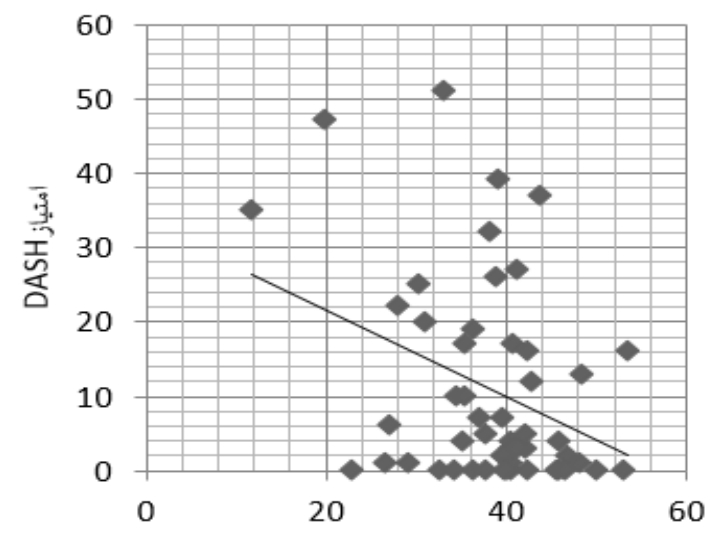

شكله. همبستخى بين قدرت جنَخَ دست غالب (كيلوكرم) و امتياز DASH

جدول r. نتايج حاصل از يرسشنامهُ DASH

\begin{tabular}{|c|c|c|c|c|}
\hline حداكثر & حداقل & انحر افمعيار & ميانتين & تروهنا \\
\hline DI & . & $\mid r / f$ & $1 \cdot / V$ & مورد \\
\hline 19 & . & $\Delta / 1$ & $F / l$ & شاهد \\
\hline
\end{tabular}

جدول r. مقايسهُ ميانكَين نتايج آزمونهاى اسكلتى ـ عضلانى دست و بازو در دو كروه مورد و شاهد

\begin{tabular}{|c|c|c|c|c|}
\hline (\%) ش شاهد/مورد & $\mathbf{p}_{\text {value }}$ & ميانكين (انحرافمعيار) & 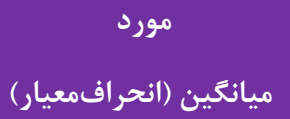 & آزمونها \\
\hline$\cdot 119$ & $\cdot 1 \cdot 1$ & $(V / T) F T / 1$ & $(\Lambda / 1) \Gamma \Lambda / r \Delta$ & قدرت كرفتن دست غالب (kg) \\
\hline$\cdot 119$ & $\cdot 1 \cdot r$ & $(\Lambda / \Gamma) \& I / G F$ & (१) rV & قدرت كرفتن دست غيرغالب (kg) \\
\hline$\cdot 119$ & $\cdot / \cdot V$ & $(N / T)$ Tr/GT & $(\Delta / 9) \mid 9 / 91$ & قدرت انخشتان دست غالب (kg) \\
\hline$\cdot \mid \Lambda \Lambda$ & $\cdot 1 \cdot f$ & $(\boldsymbol{r} / \boldsymbol{F}) \boldsymbol{r} \mathbf{T} / \boldsymbol{r}$. & $(\Delta / T) \backslash 1 / 99$ & قدرت انخشتان دست غيرغالب (kg) \\
\hline .199 & $\cdot / 4$ & $(r / I)|F / T|$ & $(1 / 9) 17 / 99$ & جابكى دست غالب (Score) \\
\hline .190 & $\cdot 11$ & $(T / r)|Y / T|$ & (1/9) $1 \% / \Delta 9$ & حابكى دست غيرغالب (Score) \\
\hline$\cdot \mid \Lambda \Lambda$ & $\cdot / \cdot V$ & $(F) Y I / V \Delta$ & $(r / 9) 19 / 1 V$ & $\begin{array}{c}\text { جابكى هر دو دست بهطور همزمان } \\
\text { (Score) }\end{array}$ \\
\hline .194 & $\cdot / 4$ & $(1 / \Gamma) \Delta / \wedge \Delta$ & $(1 / T) \Delta / \Delta$ & مونتازكردن (score) \\
\hline
\end{tabular}


با نتايج حاصل از تست احياى دماى دستان ارتباط معنادارى

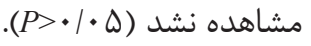

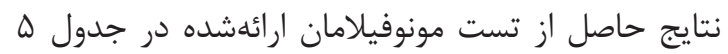

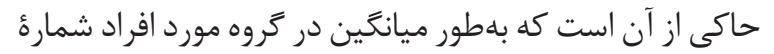

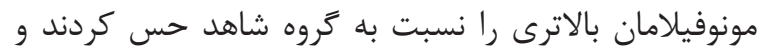

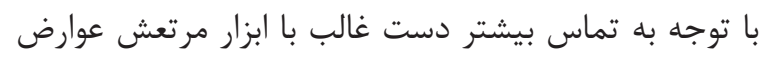

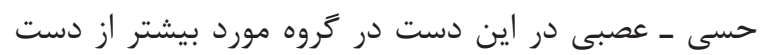

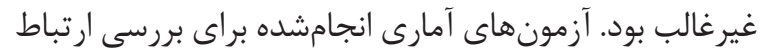

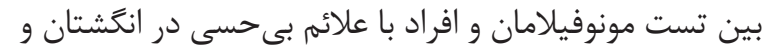

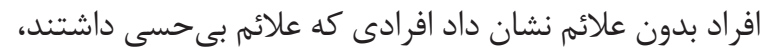

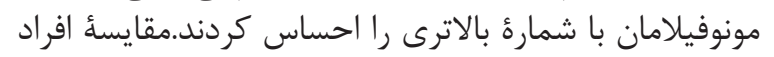

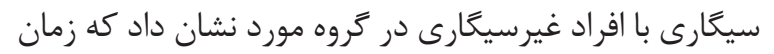

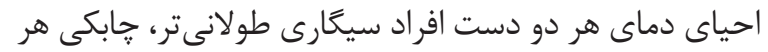

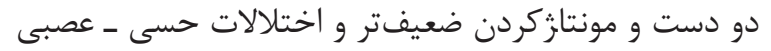

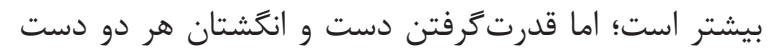
در افراد سيخارى بالاتر از افراد غير سيكارى است است

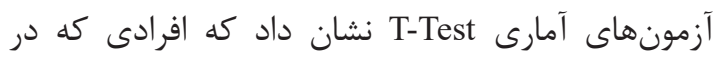

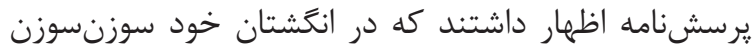

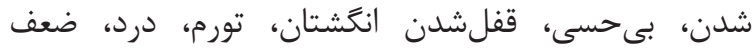

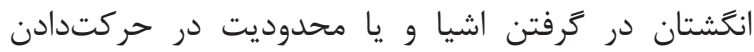

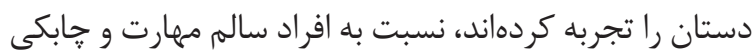

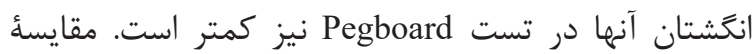

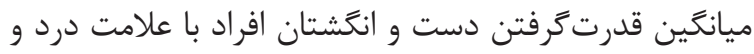

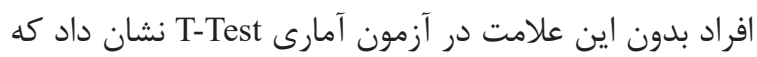

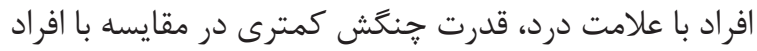

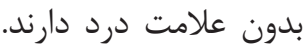

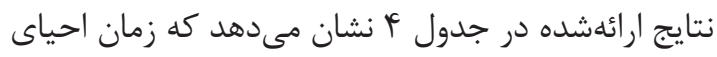

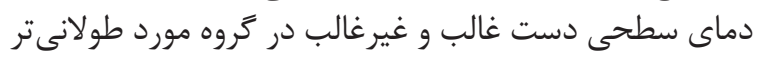

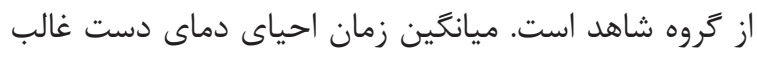

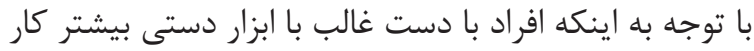

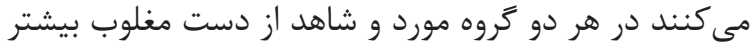

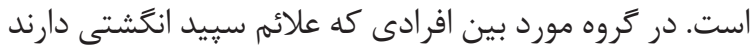

جدول F. مقايسُٔ ميانكَين نتايج آزمون عروقى دست و بازو در دو كروه مورد و شاهد

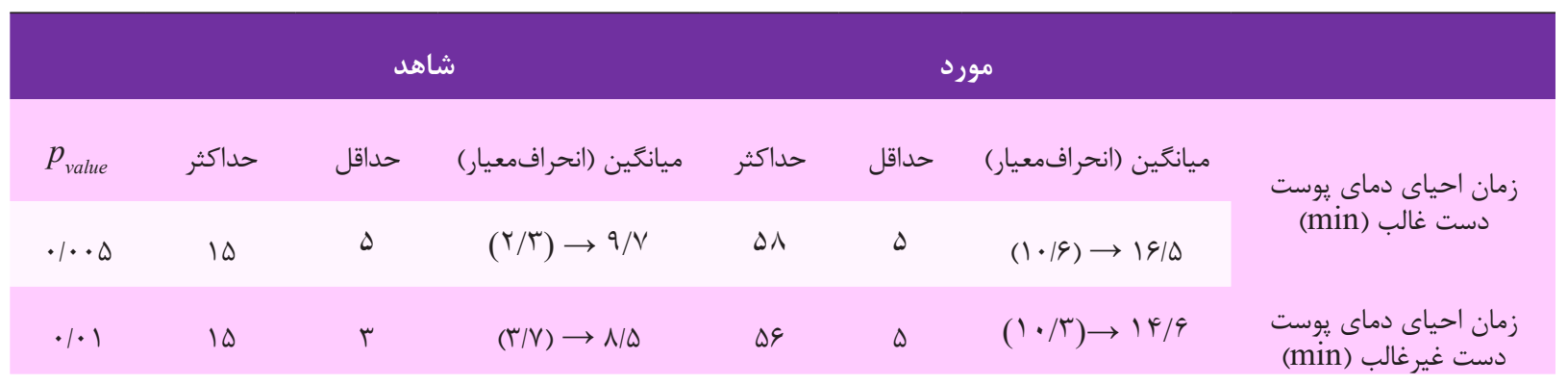

جدوله. مقايسٔ ميانكَين نتايج آزمون مونوفيلامان دست و بازو در دو َروه مورد و شاهد

\begin{tabular}{|c|c|c|c|}
\hline$p_{\text {value }}$ & 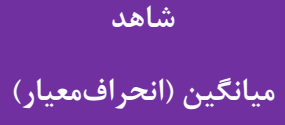 & 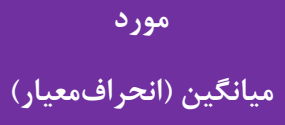 & آزمونها \\
\hline$\cdot / r$ & $(\cdot / 9) T / T F$ & $(\cdot / \Lambda) T / F V$ & حسى ـ عصبى دست غالب \\
\hline$\cdot / 1$ & $(\cdot / 9) r / \cdot r$ & (•/9) $) / T 4$ & حسى ـ عصبى دست غيرغالب \\
\hline
\end{tabular}

از طريق دستگًاه سنغ سمباده، نشان داده شد استفاده از

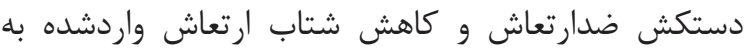

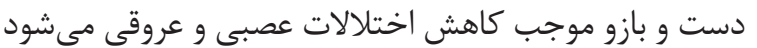
[rV]

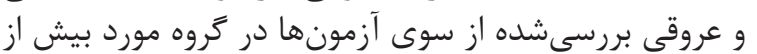

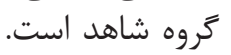

نتايج حاصل از تستهاى عروقى مطالعات انجامشده از

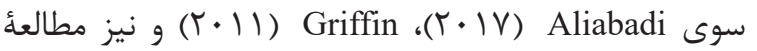

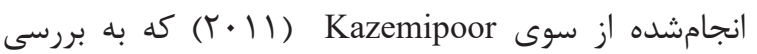

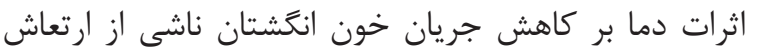

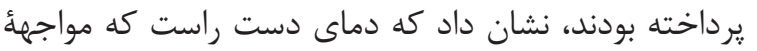

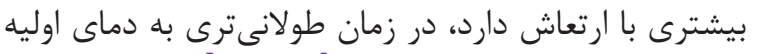

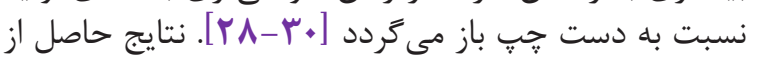

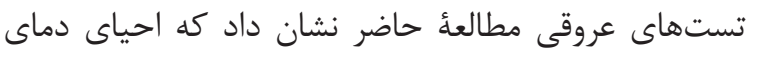

هدف از اين مطالعه بررسى سطح ناتوانى عملكرد دستى

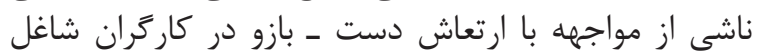

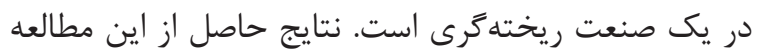

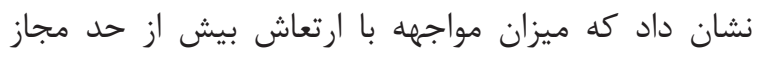

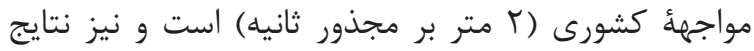

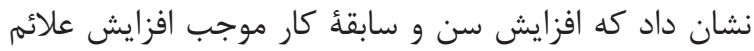

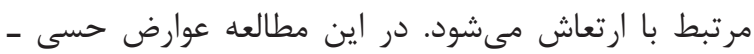

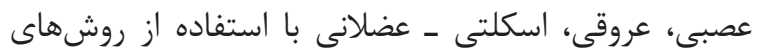

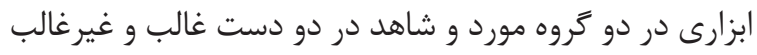

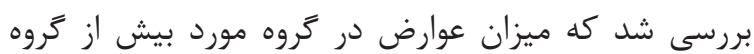

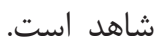

در مطالعهُ انجامشده از سوى Poorabdian (• • • • (ب) در رابطه با تأثير دستخيره ضدارتعاش بر ميزان ارتعاش ار توليدشده 
مطالعؤ انجامشده با عنوان نوروياتى ناشى از ارتعاش از

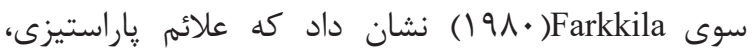

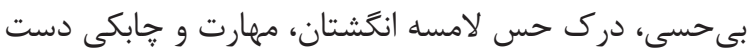

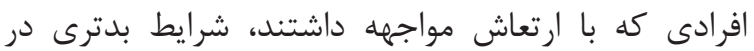

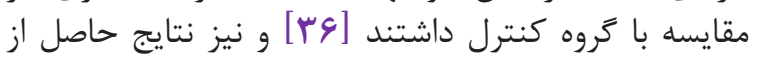

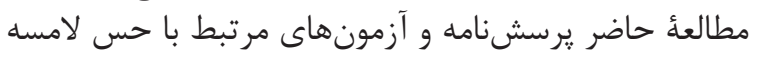

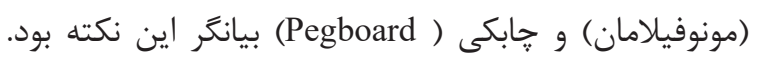

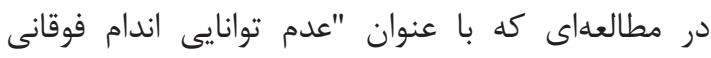

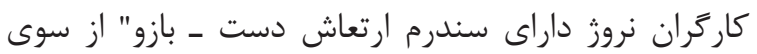

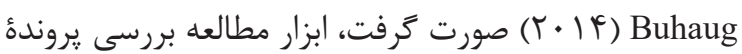

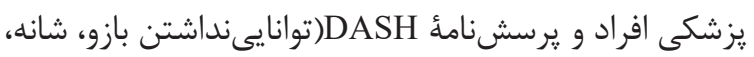

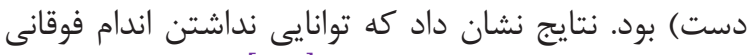

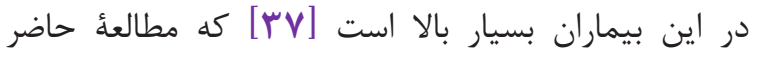

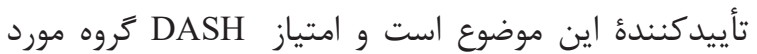

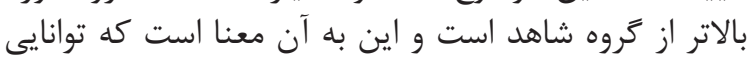

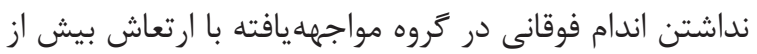
كروه شاهد است.

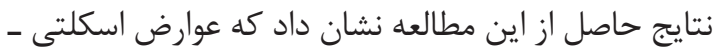

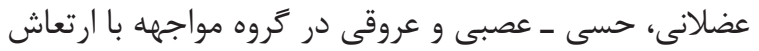

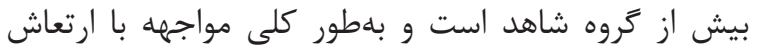

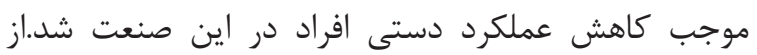

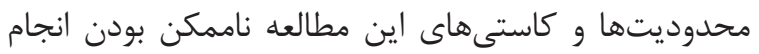

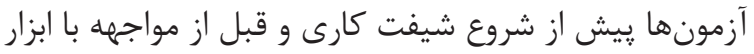

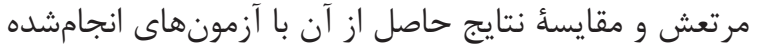

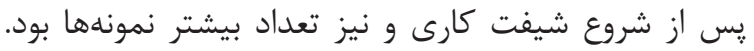

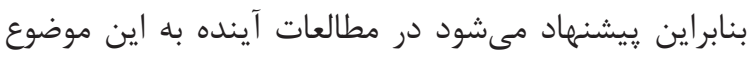

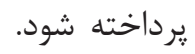

\section{نتيجه كيرى}

عملكردهاى فيزيكى دستى در شاغلين در مر مواجهائ

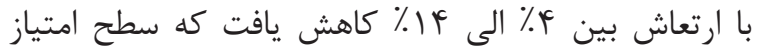
هASH

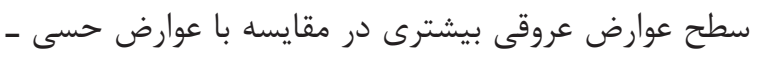
عصبى نشان دادند.

\section{سياسگزارى}

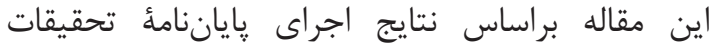

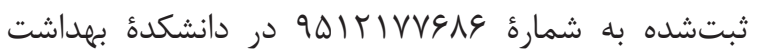

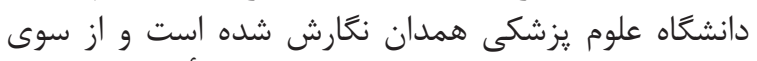

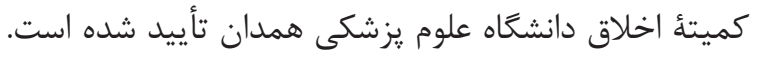

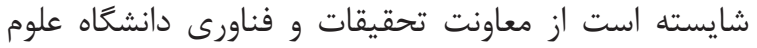

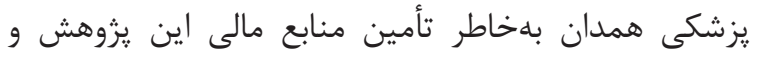

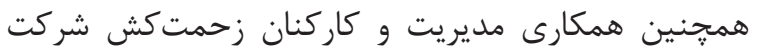

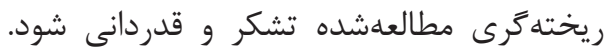

$$
\text { تعارض منافع }
$$

بين نويسند كان هيجَّونه تعارضى در منافع وجود ندارد.
دست غالب طولانىتر از دست مغلوب است و با توجه به اينكه

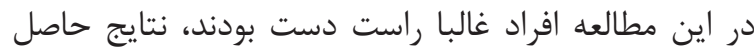

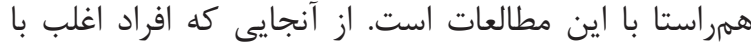

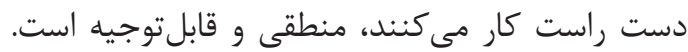

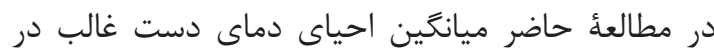

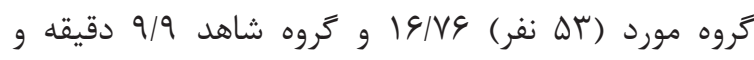

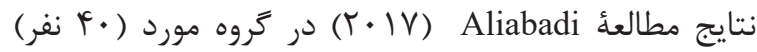

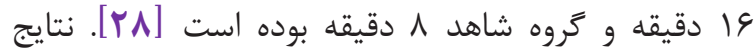

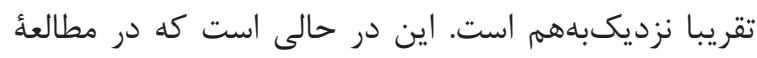
Kazemipoor

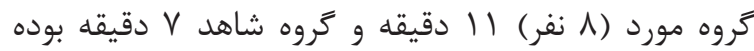

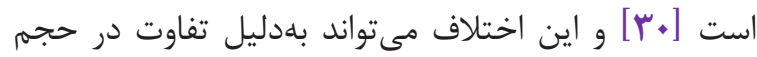

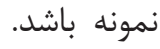

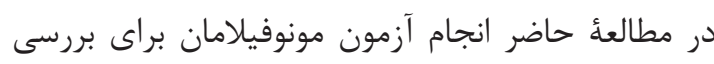

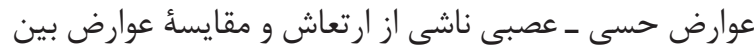

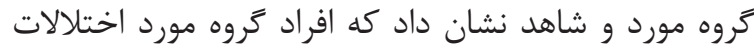

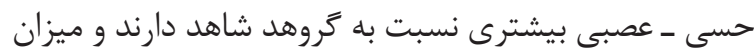

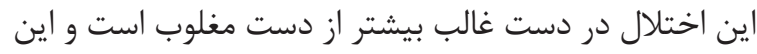

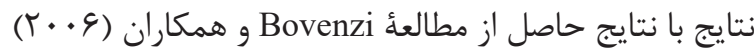

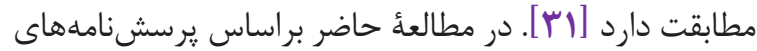

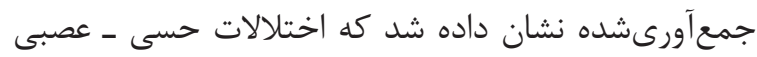

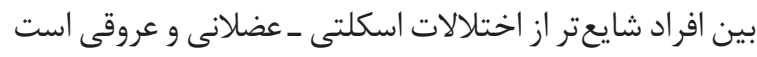

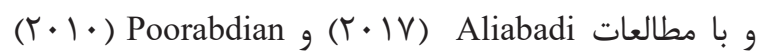

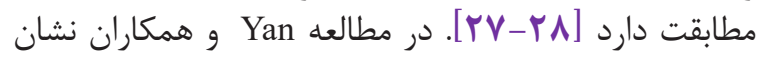

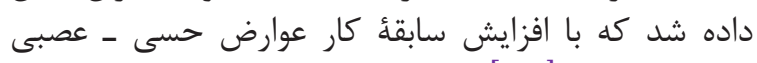

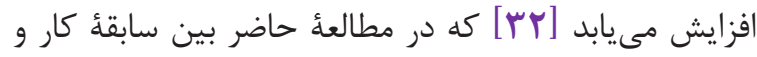

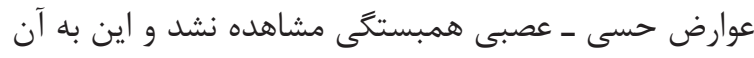

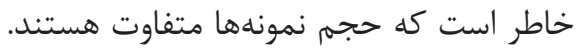
نتايج تستهاى انجامشده بهمنظور بررسى قدرت و و مهر مهارت

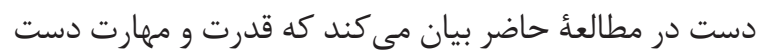

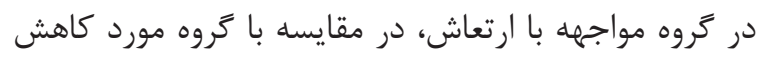

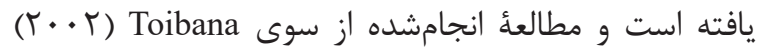

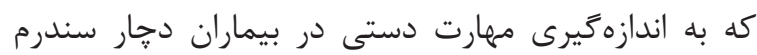

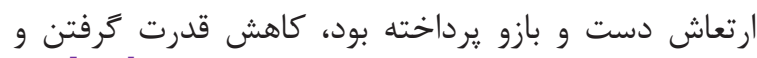

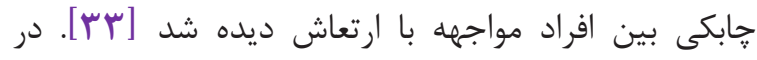

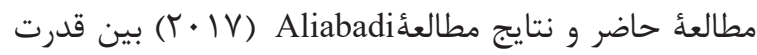

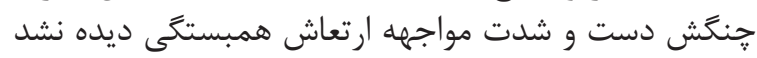

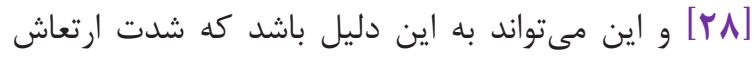

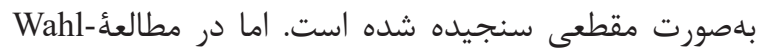
أس ström

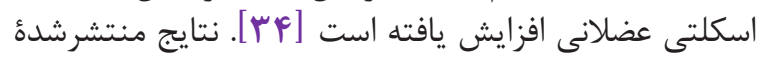

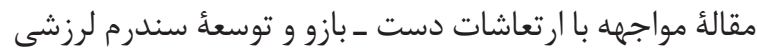

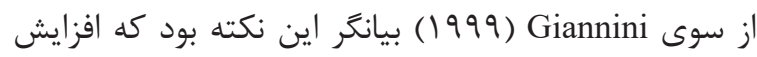

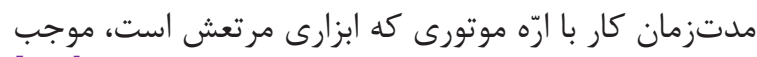

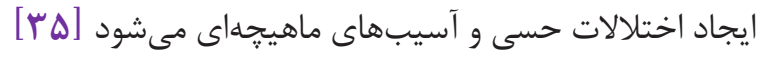
كه با نتايج حاصل از مطالعة حاضر همراسئهائ ماهيجاي است. 


\section{Reference:}

1. 1. Palmer KT, Harris C, Harris EC, Griffin MJ, Bennett J, Reading I, et al. Case-control study of low-back pain referred for magnetic resonance imaging, with special focus on whole-body vibration. Scand J Work. 2008;34(5):364-73. https:// doi.org/10.5271/sjweh.1282

2. 2. ANSI: Guide for the measurement and evaluation of human exposure to vibration transmitted to the hand (ANSI5334-1986) New York: ANSI, 1986.

3. 3. Palmer KT, Griffin MJ, Syddall HE, Pannett B, Cooper C, Coggon D. Exposure to hand-transmitted vibration and pain in the neck and upper limbs. Occup Med (Lond). 2001;51(7):4647. $\quad$ https://doi.org/10.1093/occmed/51.7.464 PMID: $\underline{11719617}$

4. 4. Golmohammadi R. Noise and vibration engineering.4nd ed. Hamadan: Hamadan publisher; 2010. p.367-422.

5. 5. Dong R, Rakheja S, Schopper A, Han B, Smutz W. Hand-transmitted vibration and biodynamic response of the human hand-arm. a critical review. Crit Rev Bio Eng. 2001;29(4):393-439. PMID: 11822480

6. 6. Wilhite CR. Pneumatic tool hand-arm vibration and posture characterization involving US navy shipboard personnel. Florida: University of South Florida; 2007.

7. 7. Mirzaei R, Biglari H, Beheshti MH, Fani MJ, Arash K. Assessment of workers' exposure to hand-arm and whole body vibration in one of the furniture industries in east of Tehran. Iran J Health Saf Environ. 2015;2(1):196-203. http:// www.ijhse.ir/index.php/IJHSE/article/view/72

8. 8. Bovenzi M. Health effects of mechanical vibration. G Ital Med Lav Ergon. 2005;27(1):5864. PMID: 15915675

9. 9. Miles I, Keenan M, Kaivo-Oja J. Handbook of knowledge society foresight. Dublin: European Foundation for the Improvement of Living and Working Conditions; 2015.

10. 10. Lay-Ekuakille A, Vendramin G, Trotta A. Spirometric measurement postprocessing: expiration data recovery. IEEE Sensors Journal. 2010;10(1):25-33. https://doi.org/10.1109/ JSEN.2009.2035743

11. 11. Bayat R, Aliabadi M, Golmohammadi R, Shafiee Motlagh M. Assessment of Exposure to Hand-Arm Vibration and its Related Health Effects in Workers Employed at Stone Cutting Workshops of Hamadan City. J Occup Hyg Eng. 2016;3(1):25-32. http://johe.umsha.ac.ir/article1-157-en.html
12. 12. National Institute for Occupational Safety and Health. Vibration white finger disease in US workers using pneumatic chipping and grinding hand tools. In: Epidemiology (Publication No 82118). Cincinnati: US Department of Health and Human Services (NIOSH); 1982.

13. 13. Neghab M, Kasaeinasab A, Yousefi Y, Hassanzadeh J, Sarreshtedar H, Alighanbari N. Health Effects of Long-term Occupational Exposure to Whole Body Vibration: A Study on Drivers of Heavy Motor Vehicles in Iran. J Health Sci Surveillance Sys . 2016;4(2):76-82. http://jhsss. sums.ac.ir/index.php/jhsss/article/view/150

14. 14. Coggins MA, Mccallig M, Paddan G, Moore K. Evaluation of hand-arm and whole-body vibrations in construction and property management. Ann Occup Hyg. 2010;54(8):904-14. https://doi. org/10.1093/annhyg/meq064 PMID:20876665

15. 15. Dimitrova T, Karaslavova E. Vibrations in the working environment and risk of acute myocardial infarction. Meditsinski Pregled/Medical Review. 2008;44(4):54-7.

16. 16. Björ B, Burström L, Nilsson T, Reuterwall C. Vibration exposure and myocardial infarction incidence: the VHEEP case-control study. Occup Med (Lond). 2006;56(5):338-44. https://doi. org/10.1093/occmed/kq1024 PMID: $\underline{16717050}$

17. 17. Key MM, Henschel AF, Butler J, Ligo RN, Tabershaw IR. Occupational diseases: a guide to their recognition. Occupational diseases: A guide to their recognition: US Department of Health, Education and Welfare; 1977.

18. 18. Azmir NA, Ghazali MI, Yahya MN, Ali MH. Hand-arm vibration disorder among grass-cutter workers in Malaysia. Int J Occup Saf Ergon. 2016;22(3):433-8. https://doi.org/10.1080/1080 $\underline{\text { 3548.2016.1150571 PMID:27050159 }}$

19. 19. Costa N, Arezes PM, Melo RB. Effects of occupational vibration exposure on cognitive/motor performance. Int J Ind Ergon. 2014;44(5):65461. https://doi.org/10.1016/j.ergon.2014.07.005

20. 20. Gerhardsson L, Hagberg M. Work ability in vibration-exposed workers. Occup Med (Lond). 2014;64(8):629-34. $\quad$ https://doi.org/10.1093/ occmed/kqu121 PMID:25145484 PMCID:PMC4239793

21. 21. Choy N, Sim CS, Yoon JK, Kim SH, Park HO, Lee JH, et al. A Case of Raynaud's Phenomenon of both Feet in a Rock Drill Operator with Hand-arm Vibration Syndrome. Korean J Occup Environ Med. 2008;20(2);119-26.

22. 22. Sampson E. Development and testing of a screening tool for mine workers with possible hand arm vibration syndrome. J Ergonom Soci S Africa. 2006;18(1):2-13. http://hdl.handle. 
net $/ 2263 / 28413$

23. 23. Laskar Md S, Harada N. Different Conditions of Cold Water Immersion Test for Diagnosing.Hand-Arm Vibration Syndrome. Environ Health Prev Med. 2005;10(6):351-9. https:// doi.org/10.1007/BF02898196 PMID:21432119 PMCID:PMC2723502

24. 24. Roberts AE, Nicholls PG, Maddali P, Van Brakel WH. Ensuring inter-tester reliability of voluntary muscle and monofilament sensory testing in the INFIR Cohort Study. Lepr Rev. 2007;78(2):122-30. PMID: 17824482

25. 25. Blankevoort CG, Van Heuvelen MJ, Scherder EJ. Reliability of six physical performance tests in older people with dementia. Phys Ther. 2013;93(1):69-78. $\quad$ https://doi.org/10.2522/ ptj.20110164 PMID:22976448

26. 26. Amirjani N, Ashworth NL, Olson JL, Morhart M, Chan KM. Validity and reliability of the Purdue Pegboard Test in carpal tunnel syndrome. Muscle Nerve. 2011;43(2):171-7. https://doi. org/10.1002/mus.21856 PMID:21254080

27. 27. Pourabdian S, Habibi E, Sadegi M, Rismanchian M. Effect of anti vibration handle use on hand grinding machine vibration. J Health Syst Res. 2010;6(1):124-32. http://hsr.mui.ac.ir/index. php/jhsr/article/view/22

28. 28. Aliabadi M, Bayat R, Golmohammadi R, Farhadian M, Esmaeil Taghavi SM. Health Effects and Work Disability Caused by Exposure to Hand-Transmitted Vibration Among Stone Cutting Workers. Acoust Aust. 2017;45(2):471-82. https://doi.org/10.1007/s40857-017-0088-5

29. 29. Ye Y, Griffin MJ. Effects of temperature on reductions in finger blood flow induced by vibration. Int Arch Occup Environ Health. 2011;84(3):315-23. https://doi.org/10.1007/ s00420-010-0560-0 PMID:20628755

30. 30. Jafari M, Kazemi Poor M. Examine the relationship between hand and arm Rynvdvartash worker of industrial unit. Several National con- ference on health occupational safety; MAY; Ghazvin 2011.

31. 31. Bovenzi M, Griffin M, Hagberg M. Diagnosis of injuries caused by hand-transmitted vibration-2nd International workshop. Report from Occupational and Environmental Medicine. (114). Sweden publisher; 2006.

32. 32. Yan J, Matloub HS, Zhang L-L, Sanger JR, Yan $^{1}$ Y, Riley DA, et al. Measuring physiological and biochemical changes in work-related vibration. First American Conference on Human Vibration [vp] 2006; 2006.

33. 33. Toibana N, Ishikawa N, Sakakibara H. Measurement of manipulative dexterity in patients with hand-arm vibration syndrome. Int Arch Occup Environ Health. 2002;75(1-2):106-10. PMID: $\underline{11898869}$

34. 34. Wahlström J, Burström L, Hagberg M, Lundström R, Nilsson T. Musculoskeletal symptoms among young male workers and associations with exposure to hand-arm vibration and ergonomic stressors. Int Arch Occup Environ Health. 2008;81(5):595-602. h https://doi.org/10.1007/ $\underline{\text { s00420-007-0250-8 PMID:17924132 }}$

35. 35. Giannini F, Rossi S, Passero S, Bovenzi M, Cannava G, Mancini R, Cioni R, Battistini N. Multifocal neural conduction impairment in forestry workers exposed and not exposed to vibration. Clin Neurophysiol. 1999;110(7):1276-83. http:// dx.doi.org/10.1016/S1388-2457(99)00062-0 PMID: 10423193

36. 36. Farkkila M, Pyyko I, Korhonen O, Starck J. Vibration-induced Decrease in the Muscle Force in Lumberjacks. Eur J Appl Physiol Occup Physiol. 1980;43(1):1-9. PMID:7371623

37. 37. Buhaug K, Moen BE, Irgens $\AA$. Upper limb disability in Norwegian workers with hand-arm vibration syndrome. J Occup Med Toxicol. 2014;9(1):5. https://dx.doi. org/10.1186\%2F1745-6673-9-5 PMID:24517340 PMCID:PMC3926262 